\title{
To what extent does climate explain variations in reported malaria cases in early $20^{\text {th }}$ century Uganda?
}

\author{
Adrian M. Tompkins, ${ }^{1}$ Laragh Larsen, ${ }^{2}$ Nicky McCreesh, ${ }^{3}$ David Taylor ${ }^{4}$ \\ ${ }^{1}$ Abdus Salam International Centre for Theoretical Physics, Trieste, Italy; ${ }^{2}$ Trinity College \\ Dublin, Dublin, Ireland; ${ }^{3}$ Department of Infectious Disease Epidemiology, London School \\ of Hygiene and Tropical Medicine, London, UK; ${ }^{4}$ Department of Geography, National \\ University of Singapore, Singapore
}

\begin{abstract}
Malaria case statistics were analysed for the period 1926 to 1960 to identify inter-annual variations in malaria cases for the Uganda Protectorate. The analysis shows the mid-to-late 1930s to be a period of increased reported cases. After World War II, malaria cases trend down to a relative minimum in the early 1950 s, before increasing rapidly after 1953 to the end of the decade. Data for the Western Province confirm these national trends, which at the time were attributed to a wide range of causes, including land development and management schemes, population mobility, interventions and misdiagnosis. Climate was occasionally proposed as a contributor to enhanced case numbers, and unusual precipitation patterns were held responsible; temperature was rarely, if ever, considered. In this study, a dynamical malaria model was driven with available precipitation and temperature
\end{abstract}

Correspondence: Adrian M. Tompkins, Abdus Salam International Centre for Theoretical Physics, Strada Costiera 11, 34151 Trieste, Italy.

Tel: +39.040 .2240111 - Fax: +39.040 .224163 .

E-mail: tompkins@ictp.it

Key words: Africa; Archive; Variability and change; Model; Vector-borne disease.

Acknowledgements: this research was supported by the European Commission's Seventh Framework Research Programme, specifically the research projects QWeCI (Quantifying Weather and Climate Impacts on health in developing countries, grant agreement 243964) and HEALTHY FUTURES (grant agreement 266327). John Christy is thanked for advice concerning the historical temperature data as is Poonam Saksena-Taylor for help with Figure 1. The malaria model data used in this manuscript are available to the public by contacting the lead author directly, while all climate data were freely available online at the specified links.

Note: See online Appendix for Climate data reconstruction.

Received for publication: 18 August 2015.

Revision received: 14 January 2016.

Accepted for publication: 5 February 2016.

(C) Copyright A.M. Tompkins et al., 2016

Licensee PAGEPress, Italy

Geospatial Health 2016; 11(s1):407

doi:10.4081/gh.2016.407

This article is distributed under the terms of the Creative Commons Attribution Noncommercial License (CC BY-NC 4.0) which permits any noncommercial use, distribution, and reproduction in any medium, provided the original author(s) and source are credited. data from the period for five stations located across a range of environments in Uganda. In line with the historical data, the simulations produced relatively enhanced transmission in the 1930s, although there is considerable variability between locations. In all locations, malaria transmission was low in the late 1940s and early 1950s, steeply increasing after 1954. Results indicate that past climate variability explains some of the variations in numbers of reported malaria cases. The impact of multiannual variability in temperature, while only on the order of $0.5^{\circ} \mathrm{C}$, was sufficient to drive some of the trends observed in the statistics and thus the role of climate was likely underestimated in the contemporary reports. As the elimination campaigns of the 1960s followed this partly climate-driven increase in malaria, this emphasises the need to account for climate when planning and evaluating intervention strategies.

\section{Introduction}

As a major vector borne disease, malaria has distinct climate drivers, with the transmission season defined by the occurrence of rains, and temperature clearly demarking where transmission is possible (Craig et al., 1999). As a consequence, year-to-year climate variability has the potential to cause anomalous transmission while longer term climate trends may cause the regions subject to epidemic and endemic transmission to shift in time (Pascual et al., 2006, 2008). At the same time, social vulnerability to the disease is shaped by a myriad of other environmental and socio-economic factors that are often difficult to separate (Kienberger and Hagenlocher, 2014). Population movements, conflict, health service breakdown, famine, land use change, drug resistance and mass interventions all impact interannual variability in transmission as well as interannual to multidecadal trends.

Attributing malaria variations to climatic and diverse non-climatic effects is complex. As an example, the resurgence of malaria in the eastern Africa highlands has been variously attributed to both climatic (Patz et al., 2005; Pascual et al., 2006; Omumbo et al., 2011) and nonclimatic factors (Lindblade et al., 2000; Bødker et al., 2000; Carter and Mendis, 2002; Nkurunziza et al., 2011). Part of the difficulty of discerning malaria drivers lies with the brevity of modern digital health records, which on a country scale generally cover less than a decade (and are often subject to discontinuities as newer diagnostic and archiving technologies were introduced), although multi-decadal records are available from isolated clinics and highland plantations (Shanks et al., 2005; Thomson et al., 2006). Such short or isolated records confound effective statistical analysis tools or study with latest-generation dynamical malaria models.

Many countries have national archival records, which, while in non- 
digital form, represent a rich source of information on malaria transmission patterns, despite their qualitative and sometimes subjective nature. Using historical records to supplement the modern health records has a number of advantages in addition to extending the record length. While local drainage and land use management schemes have been used for global vector control since the 1900s (Kitron and Spielman, 1989; Konradsen et al., 2004; Walker and Lynch, 2007), the record prior to the late $1950 \mathrm{~s}$ is unaffected by mass interventions with dichlorodiphenyltrichloroethane (DDT). Moreover, while mass population movements have always occurred, general population mobility was far below today's unprecedented levels Tatem et al. (2012). Historical records have been used in Africa to understand how socio-economic factors, such as population movements and urbanisation, have affected disease transmission (Lindsay and Martens, 1998; Shanks et al., 2005; Talisuna et al., 2015).

The attribution of disease drivers is often necessarily qualitative and frequently fails to consider environmental and particularly climate factors as drivers of transmission. This situation could possibly be improved if analysis of data and written accounts of malaria could be combined with efforts to model the expected transmission trends and variations driven by climate and/or other boundary conditions. Such efforts are hampered by the fact that many malaria models do not account for climate factors. For example, many models are based on the compartmentalised susceptible, exposed, infectious, recovered (SEIR) approaches that model the disease progression in humans and either neglect climate or incorporate it through ad-hoc adjustments of model parameters, with the aim of fitting a particular site's historical case record. For more details of the approaches employed, the reader is referred to the comprehensive review of Mandal et al. (2011).

More recently, models for malaria have been developed that aim to incorporate further details of the climate-driven parasite and vector life cycles (Depinay et al., 2004; Eckhoff, 2011; Lunde et al., 2013), and in some cases combine this with a SEI-type compartmental model of the disease progression in humans (Hoshen and Morse, 2004; Tompkins and Ermert, 2013). These models have been used to assess transmission variations for the seasons ahead (Jones and Morse, 2010, 2012; Tompkins and Di Giuseppe, 2015; MacLeod et al., 2015), or over longer multi-decadal timescales (Caminade et al., 2014; Piontek et al., 2014).

Using historical climate records to drive a malaria model could provide an indication of whether some past periods of elevated transmission are attributable, at least in part, to climate variability and change. If the periods of modelled and observed malaria anomalies coincide, and the model only accounts for climate variations, it is reasonable to hypothesise that climate played a role in driving that observed anomaly, in addition to other factors at play. However, the qualitative nature of the written reports and the considerable uncertainty in the statistics dictate that the hypothesis may not be proven, nor the amount of malaria case variability explained by climate quantified. In contrast, no correspondence between the climate-driven model runs and the historic health reports might be adequate to discount climate as a significant driver of malaria variability in the studied locations.

Here we examine the statistics presented in national historical reports for malaria in Uganda and identify broad periods when the number of cases reported appears to be enhanced. Evidence in the associated written reports was examined to determine contemporary explanations of variations in numbers of reported malaria cases, and where possible, compared to provincial and district-scale reporting relating to malaria outbreaks in Uganda and neighbouring Kenya. A mathematical model for malaria driven by historical climate records was then employed to simulate potential climate-driven malaria variations at a range of locations in Uganda, in an attempt to improve our understanding of the extent to which historical malaria variations in Uganda may be explained by climate.

\section{Materials and Methods}

\section{Location of study}

Uganda was chosen due to the availability of comprehensive annual national health summaries and digitised climate information from the 1920s onward (Figure 1). Uganda largely comprises a plateau of between 1000 and $1500 \mathrm{~m}$, with higher altitude land to the east, southwest and west. Topography underlies the spatial variations of mean annual temperatures, which range from $16^{\circ} \mathrm{C}$ in the southwestern highlands to $25^{\circ} \mathrm{C}$ in the northwest and over $30^{\circ} \mathrm{C}$ in parts of the northeast. The country experiences the main rainy season between March and May, with a second occurring between October and December. Current climate conditions facilitate stable transmission of the Plasmodium falciparum malaria parasite all year round in most of the country. Malaria is absent, or low and unstable with the potential for epidemics in the remaining part of the country.

\section{Archival health and socio-economic data}

British colonial rule of the Uganda Protectorate required the establishment of an administrative network. The administration included a Medical Department, which submitted an annual report based on a collation of information from provincial and district levels (Morris, 1978). Statistics and accounts of malaria in the Uganda Protectorate appeared frequently in the annual administrative reports, although systematic long-term analysis of the data was limited.

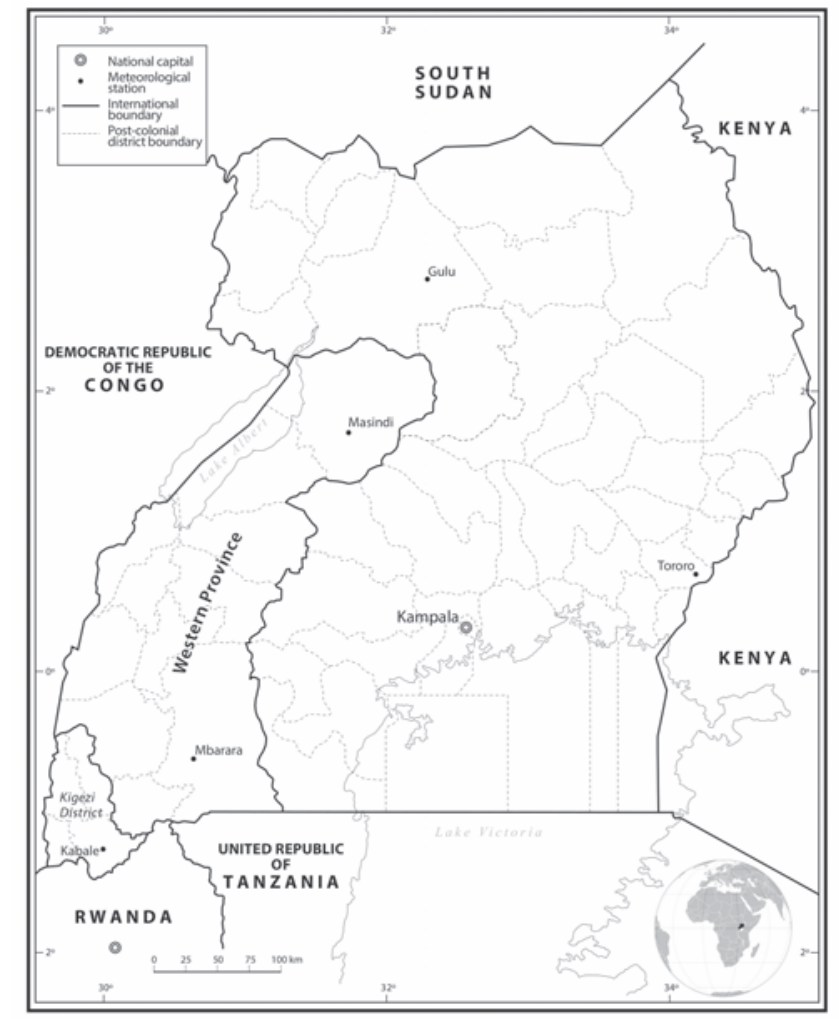

Figure 1. Map of Uganda showing the location of the five key stations at which daily precipitation data were available. The Western Administration district boundary is also highlighted. 
Medical department reports are the primary information source used here to reconstruct a timeseries history of malaria in Uganda. A number of difficulties are generally encountered when using historical documentary sources to examine past disease trends in this manner, including variations in detail, lack of certainty regarding diagnoses, and the changing methods in which quantitative data were recorded, such as frequent and in some cases undocumented variations in the locations and names of the reporting health centres. In particular, the method and categories in which the malaria statistics were recorded can vary over time, hampering their analysis in a temporally coherent manner. The data in the reports were therefore collated for the total malaria cases for the entire country. The southwestern part of the country was a particular focus (Figure 1) as its high altitude implies increased sensitivity to variations in temperature. As a consequence, this area of the country in particular has received much attention in the past, including recent debate on the potential impact of climate change on malaria in eastern Africa (Steyn, 1946; Garnham et al., 1948; De Zulueta et al., 1961, 1964; Lindsay and Martens, 1998; Mouchet et al., 1998; Kilian et al., 1999; Lindblade et al., 1999, 2000; Cox et al., 2007; Wandiga et al., 2010; Himeidan and Kweka, 2012).

Case counts were presented either in appendices and/or in tables embedded within the reports, with national totals available directly and/or as a sum total of the province values. The statistics in this work use the sum of the province values from 1912 until 1939, since the direct country totals provided for 1936-1939 show a strong discontinuity with the prior period, with case figures far smaller than the value obtained by summing the province values. Values for the period 1935 to 1939 are still likely to be slightly underestimated as Karamoja province data were unavailable. Years during World War II (WWII) (1940-1943) are excluded as they show a strong drop in cases and are likely to have been affected by the conflict (reports are very sparse during this period) and no numbers are available for 1944. After WWII, the direct country totals of in and outpatients values are used, due to the longer and more complete record (only 1951 is missing). The numbers closely match the province-derived cases total for the period 1945-1949 where both are available.

Concerning the interpretation of the statistics and the contemporary attribution of variations in numbers of reported cases, again there is considerable uncertainty, with report content and detail depending on the political and social context of the report writer. During the earlier years of the Protectorate, references to and concerns over the severity of malaria were predominantly related to the health of the European and official populations, in line with the priorities of the medical officers at the time (Beck, 1970; Doyal and Pennell, 1979). Government expenditure on the medical services was increased after World War 1 and the rural dispensary system in Uganda was established in 1924. The scope of the reports widened to encompass the whole population during the mid-1920s, which coincided with a growing confidence of Africans in western medical treatment and the expanding medical serv- ices. The analysis thus focuses on the period from the 1920 s, which is also coincident with the start year of the available historical climate data (see below), to 1960, which is when the colonial annual medical report collection in the national archives ends and large-scale intervention efforts started.

National population estimates used to normalise the national case data were obtained from http:/www.populstat.info. These are based on 10 yearly census data and an early version of the HYDE land use model (Goldewijk and Battjes, 1997; Goldewijk et al., 2010).

\section{Historical climate data}

The historical climate data also presented a number of challenges. Although data were collected at numerous stations by the British East African Meteorological Service (BEAMS) during the early $20^{\text {th }}$ century, many records remain in paper form and are yet to be digitised, and not all digitised data are freely available for research. Nevertheless, daily rainfall data for five stations are available from 1926 onward from the Global Historical Climatology Network (GHNC) database. The stations are distributed across the country from the humid highlands in the southwest to the semi-arid north of the country, with altitudes ranging from 1105 to $1869 \mathrm{~m}$ (Figure 1 and Table 1). The data are complete for the period of interest (1926-1960) with the exception of Masindi station (see Appendix for data gap filling methods).

Daily temperature data were not available for these stations in the GHNC database. However, monthly data are available from 1900 from the National Oceanic Atmospheric Administration (NOAA) global data bank for 31 stations in Uganda, including the five stations for which daily rainfall is available. Unfortunately there are many gaps in these data, sometimes spanning several years. Thus a methodology was devised to replace missing monthly temperature values and then convert to daily values (Appendix).

\section{Malaria model}

The historical climate and temperature data have been used to drive a dynamical malaria model for the five locations in Uganda. The model was used to identify those periods in the past when climatic conditions could have potentially been more suitable for malaria transmission. The malaria model used in this study is the Vector-borne disease community model of the International Centre for Theoretical Physics, Trieste (Tompkins and Ermert, 2013) and has been applied to seasonal forecasting and climate change simulations (Caminade et al., 2014; Piontek et al., 2014; Tompkins and Di Giuseppe, 2015). Vector borne disease community model of ICTP, Trieste is a mathematical biological model that represents the climate-sensitive, key life cycle processes of both the Anopheles gambiae vector and the $P$. falciparum parasite. Rainfall drives a simple representation of the surface hydrology of small temporary ponds (Asare et al., 2016a, 2016b). Temperature has multiple impacts, affecting the growth and mortality rates of Anopheles larvae, in addition to the length of the gonotrophic and sporogonic

Table 1. Daily rainfall station data from Global Historical Climatology Network of the National Oceanic Atmospheric Administration database.

\begin{tabular}{lccccc} 
Station & ID & Altitude $(\mathrm{m})$ & Latitude & Longitude & Start \\
Gulu & 63630 & 1105 & 2.75 & 32.33 & 1926 \\
Kabale & 63726 & 1869 & -1.25 & 29.98 & 1926 \\
\hline Masindi & 63654 & 1147 & 1.68 & 31.71 & 1926 \\
Mbarara & 63702 & 1413 & -0.62 & 30.62 & 1926 \\
\hline Tororo & 63684 & 1171 & 0.68 & 34.17 & 1928 \\
\hline
\end{tabular}


cycles and the mortality of adult vectors. The larvae growth and mortality rates have been modified, with the growth rates now given by Craig et al. (1999) and the mortality rate inferred from the data of Bayoh and Lindsay $(2003,2004)$.

Population density impacts the biting rate and transmission probabilities, and the model simulates lower transmission in peri-urban environments relative to rural areas, as observed by Kelly-Hope and McKenzie (2009). Population changes due to migration and population growth over time would therefore lead to transmission changes, but these cannot be explicitly modelled as accurate population data on subnational and interannual scales are unavailable. This will not greatly impact the results, however, since population growth occurs over long timescales compared with interannual climate fluctuations, and thus does not impact fluctuations in year-to-year malaria cases. A caveat is the necessary neglect of sudden, large-scale population movements due to conflict, environment disasters or forced resettlement schemes, for example. The approach used here is thus to perform a series of integrations for each climate station location to simulate a range of typical population density values, ranging from rural to urban settings. For brevity, only the experiments with the lowest and highest populationdensity values of 100 and 1000 persons $\mathrm{km}^{2}$ are discussed.

Model uncertainty was accounted for by conducting an ensemble of 58 integrations for each location and population density setting. In each of these integrations, one of the key model parameter settings was perturbed by increasing/decreasing its value by $20 \%$ (and additionally by $40 \%$ for poorly constrained parameters). The model output used in the study is the parasite ratio (PR, sometimes referred to as the parasite ratio).

\section{Results}

\section{Historical records}

The number of documented malaria cases from the national reports reveals a strong upward trend during the study period (Figure $2 \mathrm{~A}$ ). This is to be expected due to population growth, although normalising by population estimates still leaves a positive trend (Figure 2C), and highlights the increased access to and use of medical facilities by the general population and thus does not necessary reflect an increase of malaria burden over time.

The departure from a best-fit, linear relationship (Figure 2B) identifies periods when the number of cases was higher or lower than expected, emphasising year-to-year variability that could be driven by both climatic and non-climatic factors. This simple analysis reveals the period in the late 1930s as one in which cases appear to be somewhat enhanced (recalling the caveat that the direct case totals given for this period were much lower and discarded as unreliable). The post-war period also exhibits stronger interannual variability, with decreases immediately after the war until the early 1950 s, followed by steeper than average rises in the late 1950s. The interannual trends of the cases per 1000 population (Figure 2C) also show the same behaviour, with the caveat that these population data are largely based on interpolations between censuses and are thus unlikely to be able to reflect sharp population changes due to international migration or other reasons.

Data for the Western Province are available for a shorter period, but in general show similar trends to the national figures (Figure 3). The period 1930-1932 stands out as one of greater than expected cases in particular, while the four years of data available after the war hint at the downward trend seen in the national data.
The written reports corroborate the statistics to a fair degree, although it is difficult to conclude a clear picture concerning the early 1930 s, and it should be noted that these were also years of recession, and government expenditure on the medical services declined after 1931, possibly affecting treatment and subsequent reporting (Beck, 1970). That said, the Annual Medical and Sanitary Report for 1932 contains the first real attempt at a deep exploration of malaria trends in Uganda, looking beyond the number of cases treated and determining the number of cases of malaria who sought treatment at hospitals and sub-dispensaries in terms of the total number of cases of all diseases who sought treatment (Annual Medical and Sanitary Reports, 1932). It reported that a decrease in the (total) number of cases was observed this year (1932), while at the same time the report revealed a contrasting definite and considerable increase in the incidence of the disease in the Western Province, in agreement with the statistics. This would seem to

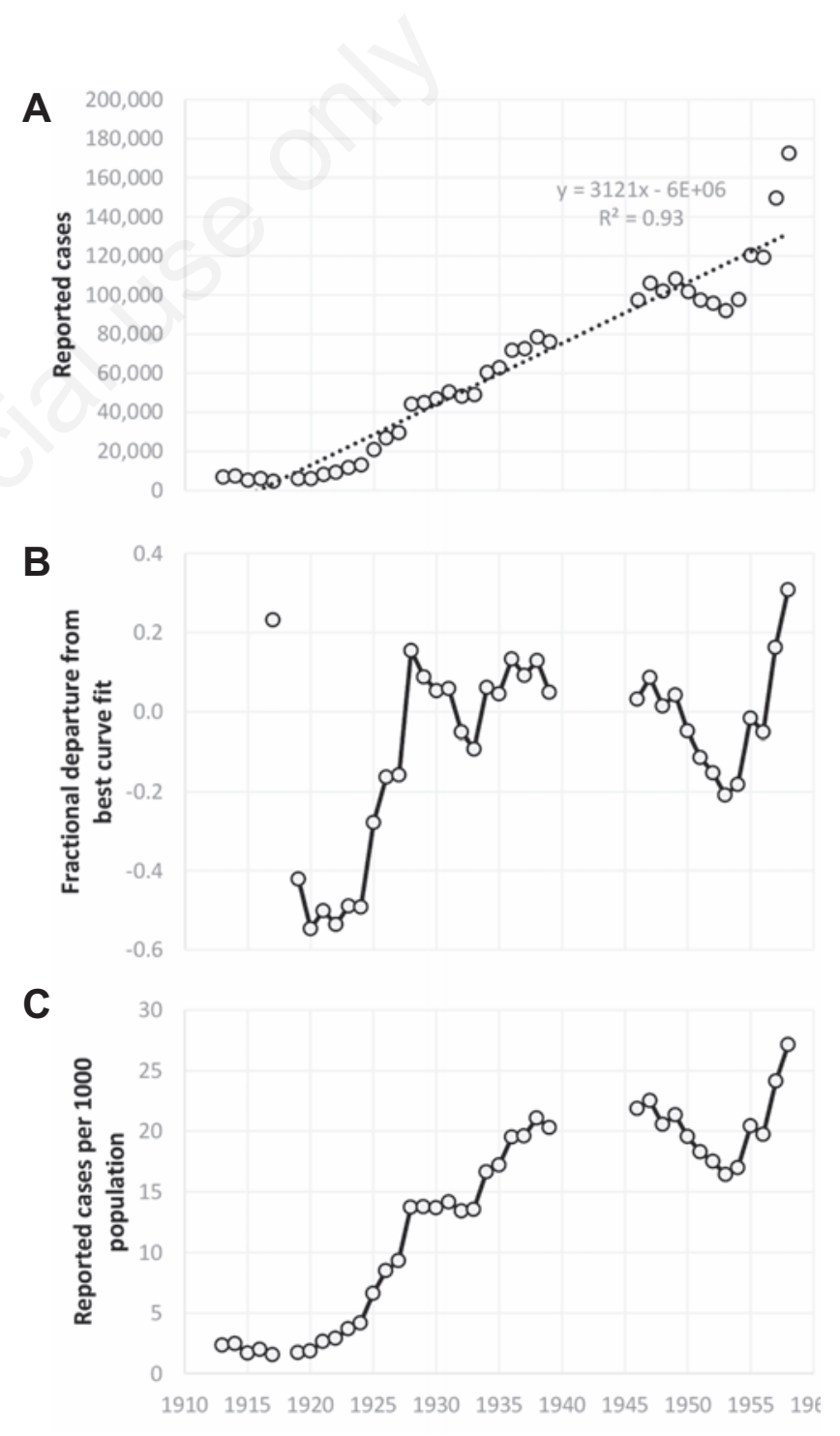

Figure 2. National statistics for reported malaria cases derived from the Ugandan annual reports. A) Total case counts for all districts (the dashed line gives the least-squares, best-fit linear relation); B) departure of cases from best-fit linear relationship; and C) cases normalised by population estimates. 
corroborate reports in Roberts (1964) and Shanks et al. (2005), that identify highland outbreaks in western Kenya in 1931 and 1932 (along with 1934, 1937 and 1940). Shanks et al. (2005) also cite the report of a severe outbreak in Kericho, Kenya during 1928 in Matson (1957). For the years 1933-1934, unusually high numbers of malaria cases in Mbarara were described with one account reflecting that It is surprising to find that Mbarara, a reputedly healthy station, returned an equal or even greater number of cases of malaria than any other place except Kampala for each of these three years (Annual Medical and Sanitary Reports, 1934).

Following this, the reports generally lack detail during WWII, during which time the national statistics were deemed unreliable for analysis. Perhaps one of the most striking references to malaria is that from 1944 when malaria was described to have occurred in epidemic proportions throughout the Protectorate (Annual Medical and Sanitary Reports, 1944). 1944 was also a notable year in neighbouring Kenya when a severe outbreak occurred in Nandi with over 600 known deaths (Roberts, 1956). At the Protectorate level the 1949 medical report described little variation in the total number of patients treated for the years 1945-1949, although unusual amounts of malaria (cases) in Kigezi district (located in southwest Uganda) were reported during 1948-1949 (Annual Medical and Sanitary Reports, 1949), while the number of reported cases were identified as falling after 1949.

During the first half of the 1950s there is little to note on malaria in Uganda from the archival reports, although towards the end of 1951 sharp outbreaks occurred in some towns described as normally free of the disease. The number of reported cases appears to have been low in 1952 in the Protectorate overall, as well as in Kigezi district, Western Province, where by 1952 malaria had been declared no longer a grave problem (Annual Medical and Sanitary Reports, 1952). By the mid1950 s it was evident that malaria was rebounding and continued to be a problem in parts of Kigezi district and in 1958 a local outbreak of malaria occurred in an area of north Kigezi normally free of the disease (Annual Medical and Sanitary Reports,1958), coinciding with the year of a large outbreak in the Ethiopian highlands (Fontaine et al., 1961). Apart from a decrease in Kigezi due to the instigation of a DDT spraying pilot project (McCrae, 1975), the rest of the Protectorate experienced notably higher prevalence during the late 1950s. The 1958 medical report reflected that it must be assumed that there has been a real rise in the incidence of malaria over the past four years (and still more over the last two) which cannot be accounted for by the general increase in numbers attending hospital for all types of illness (Annual Medical and Sanitary Reports, 1958). The reports thus tend to confirm the observed general reductions in the early 1950 s followed by a steep increase in the late 1950 s.

\section{Contemporary attribution of anomalies}

In addition to documenting anomalies in numbers of reported cases, the annual reports often attempted to attribute these anomalies to one or more of a wide range of potential causes, including land use change, migration, misdiagnosis and other data uncertainties, population vulnerability, for example through lack of immunity, and climate (summarised in Table 2). This highlights that already by the 1930 s, medical officers had a comprehensive appreciation of both the entomology and epidemiology of the disease.

Often in the reports, emphasis was placed on the entomological aspects of disease transmission, with the attribution of outbreaks or anomalies connected with surface hydrology providing availability of breeding sites and the related land use or management. For example, in the early 1940s the colonial administration had begun to encourage the drainage of swamps in the southwestern highlands to expand the amount of land available for cultivation, and investigations at the time of the 1944 outbreak suggested that cases of malaria from this area were a result of this partial drainage and cultivation of swamps (Steyn, 1946; Garnham et al., 1948), reasons that were discussed in the Annual Medical and Sanitary Reports (1947). Sometimes the attribution of

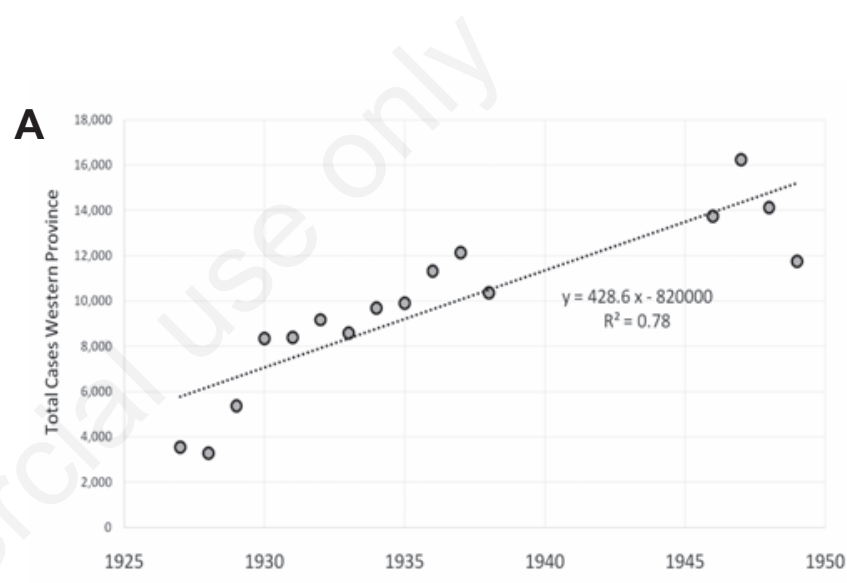

B 0.3

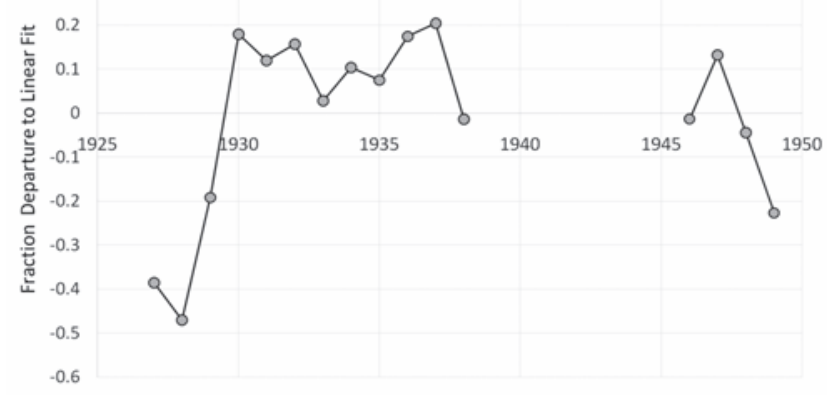

Figure 3. National statistics for reported malaria cases for the Western Province derived from the Ugandan annual reports. A) Total case counts for all districts (the dashed line gives the leastsquares best linear fit relation); B) fractional departure of cases from best-fit linear relationship.

Table 2. Summary of annual reports and literature.

\begin{tabular}{|c|c|c|}
\hline Period & Malaria notes & Reason attributed at time \\
\hline Early 1930 s & Higher transmission & Increased access to health systems, land use, migration, misdiagnosis \\
\hline 1944 & Outbreaks & Unusual rains, population movements \\
\hline $1945-1955$ & Decreasing transmission & Improved drainage and water management \\
\hline 1951 & Isolated outbreak & Unusual rains \\
\hline$\underline{1955-1960}$ & Strongly increasing malaria & ack of control, land use, poor land management in development scheme \\
\hline
\end{tabular}


malaria outbreaks could be very local in scale, with a fishpond incriminated as the cause of the 1958 outbreak in north Kigezi (Annual Medical and Sanitary Reports,1958). More generally, the rise in cases in the late 1950s was ascribed to the creation and proliferation of mosquito breeding sites associated with development projects, such as the digging of borrow-pits for the construction of new roads, irrigation projects, and the building of dams and fish ponds. A similar account was given in the Medical Department report for 1960 when it was thought almost certain that rising malaria was the result of an increase in breeding places associated with human activity (Annual Medical and Sanitary Reports, 1960).

Migration, both cyclic and permanent, has received much attention in the recent literature for its role in transporting the malaria parasite (Sevilla-Casas, 1993; Martens and Hall, 2000; Tatem and Smith, 2010; Wesolowski et al., 2012; Tatem, 2014; Tompkins and McCreesh, 2016), but the role of human migration in transporting the agent between areas of low transmission was already appreciated during the historical period (Findlay, 1946; Prothero, 1961) and often identified as the mechanism behind transmission anomalies. For example, increased cases in Mbarara in the 1930s were attributed to a large number of Banyaruanda workers passing through the district, and Western province cases in the 1950s were also associated with movement from lower altitude regions in Buganda. In neighbouring Kenya, Garnham (1945) speculated the carriers of the parasite to higher altitudes during the 1944 outbreak were itinerant agricultural workers and their families originating in malarious lowland parts of the country. Population movements were again highlighted as a likely contributing factor to the incidence of malaria in Kigezi district. During the mid-to-late 1940s, and in response to concerns regarding the over cultivation and overpopulation of parts of Kigezi district, the British administration devised a resettlement scheme that entailed the relocation of people from the more densely populated highlands to designated areas of more sparsely populated lower altitude land elsewhere in Uganda (Carswell, 2007). It was considered likely that malaria cases had predominantly occurred among the non-immune settlers who had moved from the highlands.

The reports also demonstrate a good appreciation of socio-economic and environmental issues. For example, the report for 1929 described the role of housing improvements in reducing malaria. It is interesting to note that, despite recent evidence of the effectiveness and cost efficiency of housing improvements (Ault, 1993; Lindsay et al., 2002; Atieli et al., 2009; Lwetoijera et al., 2013), they are no longer considered a front-line intervention strategy for control in Uganda. Several reports highlight the role of host immunity in determining the profile of population vulnerability. In tandem, the reports also show awareness of the uncertainties in the data themselves. The sharp increases in the late 1920 s were thought to be due more to improved diagnosis and to the greater resort on the part of the native to treatment than to an actual increase in the incidence of the disease Annual Medical and Sanitary Reports (1929), while high malaria transmission reported in the Western Province in the early 1930s may instead have reflected the introduction of typhus fever into the district, which may have been recorded as clinical malaria (Annual Medical and Sanitary Reports, 1932). The 1949 report conceded that information on malaria incidence among the general African population was less precise than that on the European and Asian populations (Annual Medical and Sanitary Reports, 1949).

What of the perceived role of climate in malaria transmission? The reports were certainly aware of climate as a driver of interannual malaria variability. When discussing the 1944 outbreak, the medical report for the year cited the unusual rains which were described to consist of light showers at frequent intervals creating circumstances favourable not only for large scale breeding of An. Gambiae but for increased longevity of the mosquito itself (Annual Medical and Sanitary Reports, 1944). Rainfall was also very low in 1943 resulting in food shortages across much of Uganda (Carswell, 2003), which was likely a contributing factor in facilitating the epidemic through increased social vulnerability. Unusual rainfall conditions were also highlighted when discussing the malaria outbreaks in the latter half of 1951, attributed to unusually prolonged rain in the later part of the year, following the lighter than normal rains during the earlier part of 1951 when malaria incidence was low (Annual Medical and Sanitary Reports, 1951). This would agree with observations in Kenya, where unusual rainfall conditions produced a highland epidemic with shifted seasonality despite ongoing control measures (Shanks et al., 2005). Overall, it is particularly noteworthy that climate variability is only considered in terms of rainfall; in no report was a mention of anomalous temperatures found. This is despite the fact that it was already well established that high altitudes with lower temperatures were associated with lower or no malaria transmission. This could be due to the fact that interannual variability in rainfall is likely more striking to the observer than anomalies in temperature and the fact that relatively minor perturbations of temperature in a highland region can have a significant impact on transmission was presumably poorly appreciated.

\section{Climate summary}

The climate during the study period 1926-1960 shows no temperature trends for the mean of the five stations (Figure 4A). This agrees with Christy (2013), who reported no strong evidence of temperature trends during the period 1920-1960 in either maximum or minimum temperature for a larger dataset of 31 stations. Christy (2013) reconstructed a Uganda-wide temperature index for minimum and maximum temperatures. The poor correlation between these two variables in the historical period compared with the modern highlighted the data

A
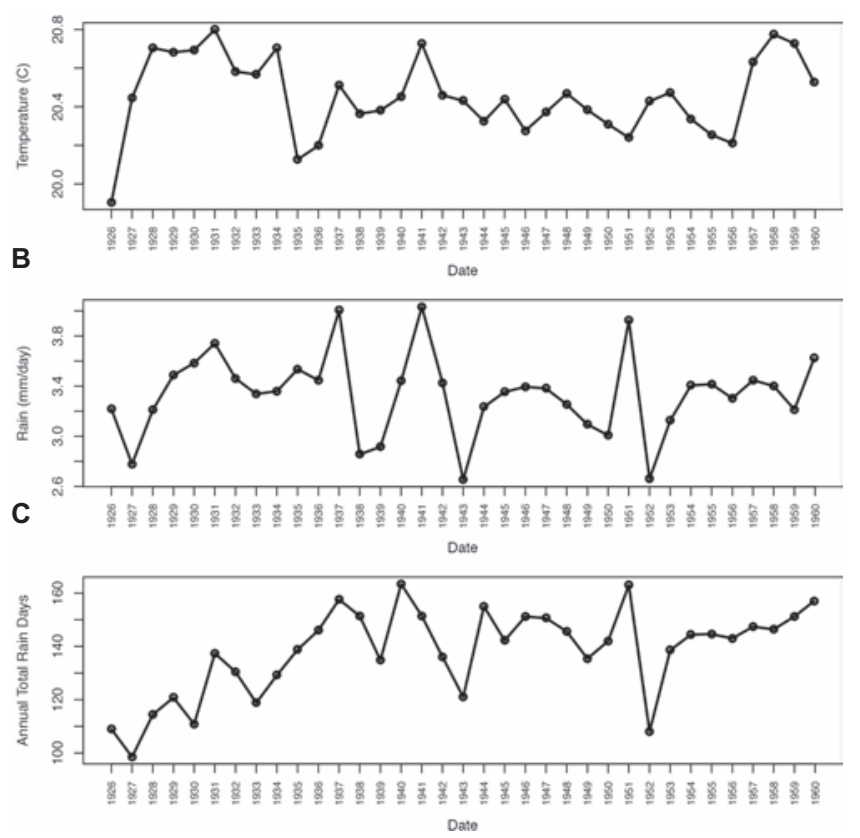

Figure 4. Temperature (A), rainfall (B), and number of rainy days (C), averaged for the five stations in Uganda used in this study. 
uncertainties at the time. Nevertheless, merging the data to produce a Uganda-wide mean index showed that the years 1926-1930, 1942 and 1959 appeared particularly warm during the period 1920-1960, although these warm years are now frequently exceeded due to the warming trend that started around 1970 in the record. For the five stations in question here, it is clear that the years 1928-1934, 1941 and 1957-1960 are almost $0.5^{\circ} \mathrm{C}$ warmer than the long-term average over the period.

Rainfall likewise exhibited no long-term trend (Figure 4B), with the wettest four years identified as 1931, 1937, 1941 and 1951. As the historical reports also attribute years of anomalous levels of reported malaria cases to conditions of frequent light rain, the daily rainfall data have been analysed to count the total number of days for which rain exceeds an arbitrarily small threshold of $0.5 \mathrm{~mm}$. Relative peaks of high numbers of rainy days occur in 1937, 1940, 1944, 1951 and 1960. The origin of the upward trend in the initial decade and whether this is real or an artifact of the measurement method changing during the period is unclear.

Rainfall in eastern Africa is influenced by both the tropical Pacific and Indian Ocean temperatures (Birkett et al., 1999; Goddard and Graham, 1999; Latif et al., 1999). Pacific variability is manifested in the El Niño-southern oscillation (ENS0) (Bradley et al., 1987), with rainfall, especially during the short rains, tending to be increased during warm ENSO events. The impact of the western Indian ocean is particularly strong and Black et al. (2003) suggest that the documented link of ENSO variability with east Africa acts mainly via its impact on the Indian ocean (Venzke et al., 2000). The effect of ENSO on temperature is tropics-wide, with the whole tropics on the order of $1^{\circ} \mathrm{C}$ warmer during warm El Niño events (Bradley et al., 1987).

The sea surface temperature (SST) anomaly in the region $5 \mathrm{~S}$ to $5 \mathrm{~N}$ and $170 \mathrm{~W}$ to $120 \mathrm{~W}$ is commonly used as an index for ENSO (referred to as the Niño3.4 index), which is shown for the period 1926 to 1960 in Figure 5, using the data of Kaplan et al. (1998). There are strong El Niño events occurring in 1925/1926 and 1930/1931 (as a benchmark, the exceptional event of 1997/1998 slightly exceeded $2.5^{\circ} \mathrm{C}$ ). An unusually long event is maintained through 1940 to 1942 , but the post-war years show little ENSO variance, with the next event occurring during 1957/1958. Verdon and Franks (2005) shows the SST anomaly index for the western Indian Ocean region ( $10 \mathrm{~S}$ to $10 \mathrm{~N}$ and $50 \mathrm{E}$ to $70 \mathrm{E}$; panel TWI in their Figure 3), and there is a close association with ENSO variability, as expected. All the warm ENSO events highlighted above correspond to a warm western Indian ocean, with the exception of the late 1950 s, during which the Indian Ocean region remains cool.

The station-mean climate summary shows some correspondence with the historical malaria data. The relatively warm 1930s and late 1950 s, for example, which would be expected to increase malaria transmission, especially in the higher altitude provinces, coincides with periods of anomalously high levels of malaria, in particular the upwards trend of 1957-60. Moreover, 1944 and 1951 were both identified as outbreak years with rainfall conditions attributed as the cause in the annual reports, and these years are both identified as anomalous in terms of rainfall amount and/or rainy days total in the station data, although the values are not unique, with 1937 also very wet but not highlighted in the malaria statistics or written reports.

The climate data also highlight the potential uncertainty in the malaria statistics and reports. For example, 1941 was shown to be both a relatively warm and wet year, both expected due to the warm ENSO event and warm Indian Ocean and one might expect this to reflect in high numbers of malaria cases. Indeed, the 1941/42 years were identified as years of intense highland epidemics in both Kenya (Githeko and Shiff, 2005) and the Usambara mountains on Tanzania (Bødker et al., 2000 ), but no mention is made of anomalous case numbers in Uganda.
It is thus reasonable to hypothesise that similar circumstances of high malaria cases may have existed in the Ugandan highlands but were not identified or recorded because of the disruptions associated with WWII.

\section{Climate driven malaria simulations}

The malaria transmission varies greatly between the sites, as expected due to their wide range of altitudes and therefore mean temperatures. For example, the highest altitude station at Kabale has a mean temperature slightly in excess of $16^{\circ} \mathrm{C}$ during the study period and therefore malaria transmission is not supported in the model. This is not to say that malaria outbreaks could not occur at this altitude, but they would require a substantial migration of infectious population into the region during an anomalously warm season, a process that is not included in the model integrations. Moreover, there is substantial horizontal variation in temperature over the complex terrain in this region and the station temperature is not likely to represent all locations.

At the lower stations of Gulu, Tororo and Masindi, all of which are situated between 1100 and $1200 \mathrm{~m}$ in altitude, malaria transmission is holoendemic or hyperendemic in rural environments, and the modelled transmission is high in each year, as is the case for the present day climate prior to the recent scale up of interventions. For these stations, variability in rural transmission from year to year due to climate is very limited and noted outbreaks are unlikely to be climate-driven. However, in higher population density settings, the transmission intensity can reduce (Kelly-Hope and McKenzie, 2009) and increased interannual variability can be simulated. This is demonstrated for the site of Tororo (Figure 6). The simulation shown in Figure 6B illustrates a rural setting with a population density of $100 \mathrm{~km}^{2}$. Climate drives variations in the seasonal characteristics, but in the absence of interventions, the PR in any case saturates each year at 60 to $80 \%$ (irrespective of model parameter settings). Instead, Figure 6a shows transmission in a highdensity rural or peri-urban setting and reveals much stronger interannual and multi-annual swings in prevalence. In this case, the PR is relatively high in the early and mid 1930s, dropping to much lower levels after 1938. With the exception of the period 1942-1944, the PR remains low until 1953, after which PR increases and is subject to a positive trend. It is notable that in this mesoendemic setting, the simulations reveal a much larger sensitivity to the model parameter settings, and perturbing a single model parameter by $20 \%$ is seen to be adequate to suppress transmission throughout the 1950s in a number of the simulations, for example. Transmission variability for the other three stations of Mbarara, Masindi and Gulu show some similarities with

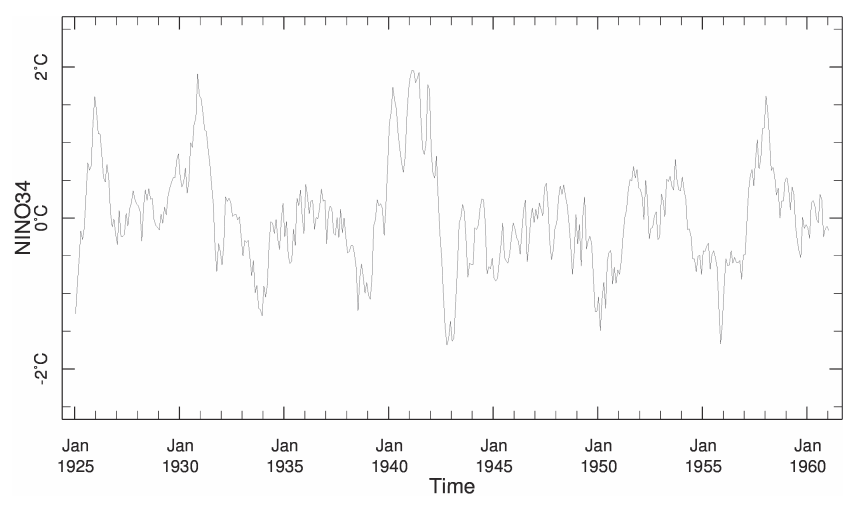

Figure 5. Monthly Niño3.4 index [sea surface temperature anomaly based on Kaplan et al. (1998) for the region $5 \mathrm{~S}-5 \mathrm{~N}$ and 170$120 \mathrm{~W}]$ during the study period. 
Tororo, but there are also considerable inter-station disparities that are likely associated with the horizontal variability in rainfall amounts and daily variability (Figure 7). The simulations for Mbarbara show high PR values for the late 1920s and the three years of 1930-1932, but then transmission practically ceases until the war years after 1942. Transmission trends downwards in the late 1940s and again ceases by 1954 (although a subset of the model ensemble members simulate some transmission). Transmission resumes in the late 1950s. The Masindi and Gulu simulations for peri-urban settings repeat this general picture, but with considerable differences concerning the period during the 1930s during when simulated transmission was high. Both of these stations show a strong positive trend in malaria transmission and prevalence setting after 1954 .

\section{Comparing the model and statistics}

Although the model simulations and observed case data are measuring different aspects of malaria, it is illustrative to compare the two series to see if there is some similarity in the broad trends. The analysis of annual departure from expected number of cases for the model output for the four key stations compared with departure from expected for the annual reported number of cases in the empirical data reveals limited similarity between the two series (Figure 8), and there is weak evidence for a correlation (default model: Spearman's rho $=0.39$, $\mathrm{P}=0.05$, ensemble mean: Spearman's rho=0.35, $\mathrm{P}=0.09$ ). For the $1930 \mathrm{~s}$, where the model simulated very contrasting responses at each location, the general downward trend is not reproduced in the data. Despite these disparities however, there is a strong correspondence in the year in which the sharp increase begins in the 1950s.

\section{Discussion}

The malaria statistics contained in the national annual reports of the Medical Department of the Ugandan Protectorate revealed some periods when numbers of reported malaria cases were higher than usual, as well as identifying some isolated years of anomalous levels on a national or local scale. The number of reported cases appeared to be somewhat higher than expected in the late 1930s, according to the statistics compiled here. A strong outbreak was noted in 1944, and after decreases in the late 1940 s and early 1950 s, the number of reported
A

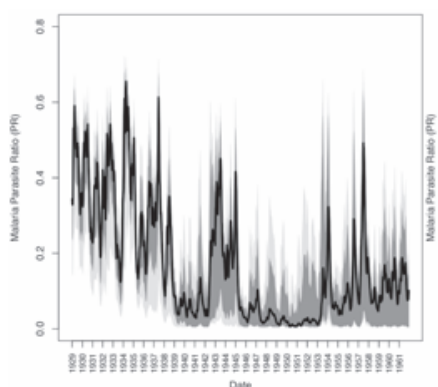

B

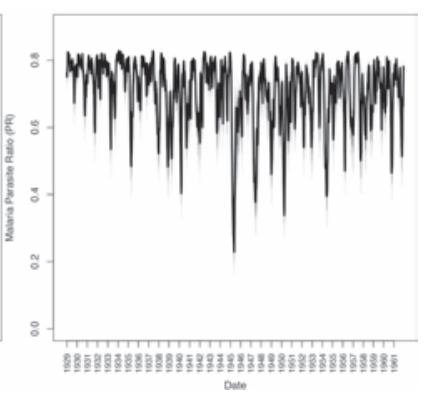

Figure 6. Tororo station malaria parasite ratio simulated for a population density of $100 \mathrm{~km}^{2}(\mathrm{~A})$ and $1000 \mathrm{~km}^{2}(\mathrm{~B})$. The timeseries of model output therefore show the default model superimposed on light and dark shading that indicates the range of the inner 90 and $50 \%$ percentiles, respectively (i.e. 90 and $50 \%$ of the simulations lie within the indicated range). cases increased strongly in the years of the late 1950s leading up to the introduction of the mass interventions conducted in the 1960s. The written reports accompanying these statistics attributed these trends to a wide variety of socioeconomic and environmental causes, although climate was relatively rarely invoked and was discussed in terms of anomalous rainfall conditions, neglecting temperature. This emphasis is often reflected in more modern analyses of outbreaks, with Lindblade et al. (1999) emphasising the role of anomalous rainfall in the 1998 outbreak in the Kenyan highlands for example, despite a considerable warm temperature anomaly that also resulted from the strong El Niño conditions. Although it is highly likely that the contemporary report writers were aware of the complex and interactive nature of the drivers of malaria, the attribution of malaria anomalies was frequently univariate or bivariate, focusing on one or two principle causes. This was most likely due to the near impossibility of ascertaining the relative contributions of drivers in this complicated system. Modelling the potential

A

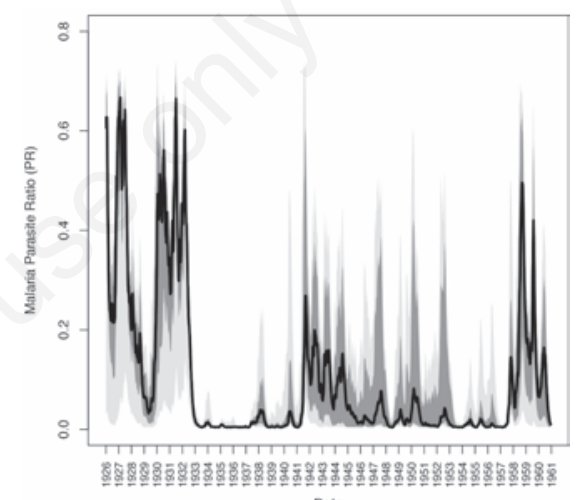

B

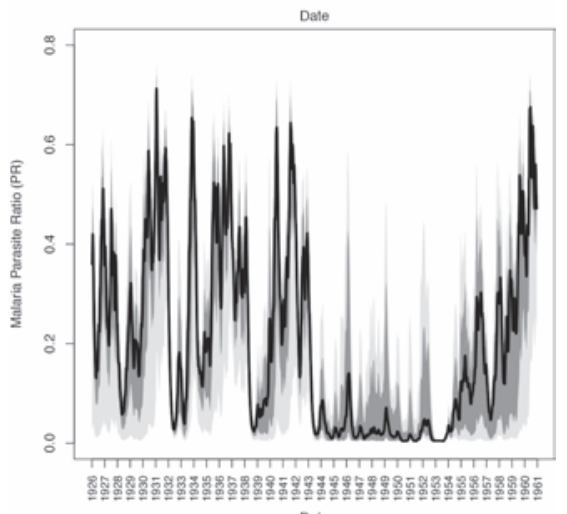

C

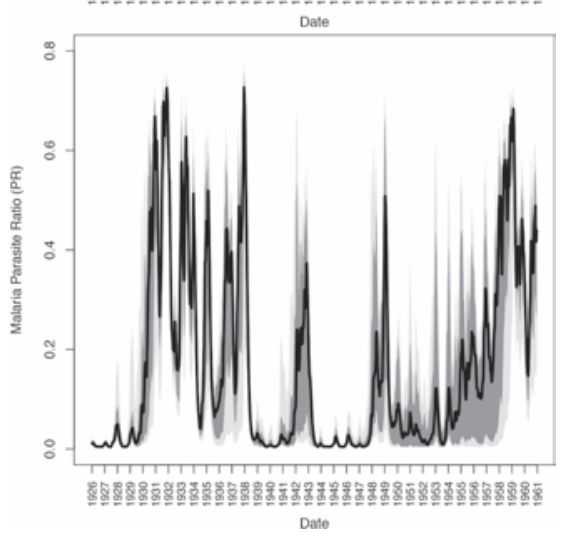

Figure 7. Malaria parasite ratio for: A) Mbarara (assuming population density of $\left.100 \mathrm{~km}^{2}\right)$; B) Masindi $\left(1000 \mathrm{~km}^{2}\right)$; and C) Gulu $\left(1000 \mathrm{~km}^{2}\right)$. 
influence of climatic factors on malaria transmission allows us to examine whether the influences of climate may have been underestimated at the time.

Driving a mathematical-biological model for malaria transmission with climate data does indeed reveal some broad tendencies that replicate some features of the malaria cases records. The simulation for four locations in Uganda indicates higher transmission in the early to mid 1930s relative to the rest of the period, although there is considerable variation between the locations, and the written reports in this period are also somewhat conflicting. Anomalously high numbers of reported cases were, however, evident in Western Province, where an outbreak was reported in 1932. The direct comparison of the two information sources is challenging, but it does appear that the relatively warm climate associated with the warm ENSO may have contributed in increasing the occurrence of malaria during this period. Strong warm ENSO conditions and a warm western Indian Ocean persisted during 1941/1942, and were likely to have resulted in the warm and anomalously wet conditions that were observed in the Ugandan climate data. These resulted in high transmission in the model simulations, which was not corroborated in the Uganda health records. The fact that malaria outbreaks were reported independently in the highlands of neighbouring Kenya and Tanzania during this period leads us to suggest that high incidence of the disease may have been missed in Uganda, perhaps due to the ongoing conflict. More robust conclusions can be drawn concerning the period of the late 1950s. The statistics and descriptions in the annual reports reveal a strong upward trend in cases, and this is clearly reproduced in the malaria model simulations, at least in part due to ENSO-related warming, indicating a clear role of climate in driving, at least in part, an increase in malaria.

Here we are not arguing that climate is the sole, or even the most important, driver of interannual variations in malaria cases. Moreover, the modelling efforts are associated with considerable caveats. The limitations of the health, climate and population datasets used in the analysis imply that the simulations can only provide a crude indication of transmission variations; like-for-like simulations of cases on a catchment scale are not possible. The malaria model itself is subject to uncertainties in its mathematical formulation and parameter settings. For example, the anomalous transmission years associated with unusual rainfall conditions were not identified in the simulations. While this could be partly due to errors and lack of representativeness of the five meteorological station datasets, this could also be due to the poor representation of the highly nonlinear relationship between rain-

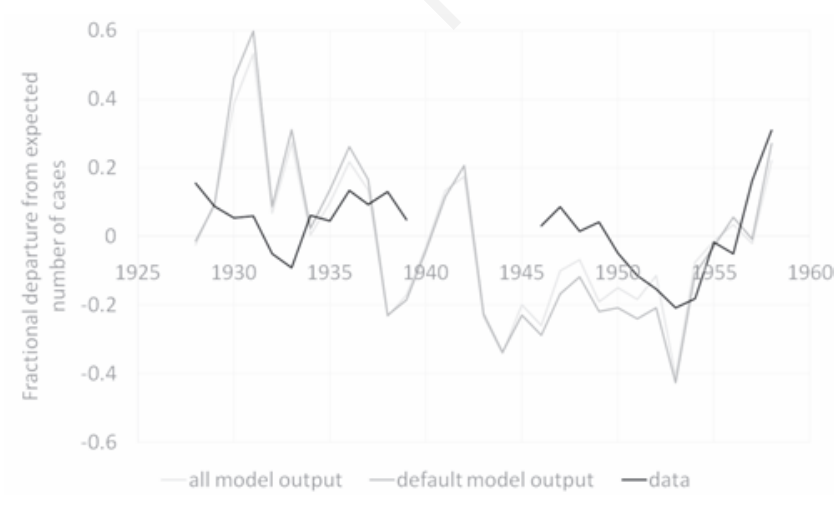

Figure 8. Malaria parasite ratio for four stations as simulated by the default Vector-borne disease community model of International Centre of the Theoretical Physics, Trieste model and the mean of the perturbed ensemble, compared to the observed total cases for Uganda. fall and breeding site availability, especially in areas of complex terrain (Lindsay and Martens, 1998).

The role of climate variability and trends relative to socio-economic factors in driving malaria transmission variation has been the subject of much recent debate (Hay et al., 2002a, 2002b; Gething et al., 2010; Alonso et al., 2011; Ermert et al., 2012; Caminade et al., 2014; Siraj et al., 2014). Here, the strong correspondence between malaria observations and climate-driven simulation in the late 1950s nevertheless reemphasises the need to include climate in the assessment of the impact of intervention strategies. The control efforts involving DDT spraying of the early 1960 s were likely superimposed on a climate-driven variability, and if the warming of the late 1950 s was subsequently reversed and rainfall levels were to decrease, as ENSO returned to a cooler La Niña state, the perceived early successes of interventions may have been exaggerated, for example. The present scaling up of efforts to combat the disease imply that this incorporation of climate information in planning and subsequent assessment of intervention strategies is perhaps more pertinent now than ever. This study indicates that we are beginning to develop malaria modelling systems that may be capable of aiding this assessment.

\section{Conclusions}

This paper highlights the possible role of climate (temperature and precipitation in particular) variability in influencing the number of malaria cases in Uganda during the documented past, and the value of recently developed dynamic disease models in simulating outbreaks based on climate and other environmental data. This role is confounded, however, by other factors. Climate therefore has some explanatory value concerning variations in the number of reported cases of malaria in the country. This ought to be taken into account when considering the effectiveness of current interventions and the possible impacts of projected future changes in climate.

\section{References}

Alonso D, Bouma MJ, Pascual M, 2011. Epidemic malaria and warmer temperatures in recent decades in an East African highland. P Roy Soc Lond B Bio 278:1661-9.

Annual Medical and Sanitary Reports, 1929. Uganda Sessional Papers C0685. The National Archives London, London, UK.

Annual Medical and Sanitary Reports, 1932. Uganda Sessional Papers C0685. The National Archives London, London, UK.

Annual Medical and Sanitary Reports, 1934. Uganda Sessional Papers C0685. The National Archives London, London, UK.

Annual Medical and Sanitary Reports, 1944. Uganda Sessional Papers C0685. The National Archives London, London, UK.

Annual Medical and Sanitary Reports, 1947. Uganda Sessional Papers C0685. The National Archives London, London, UK.

Annual Medical and Sanitary Reports, 1949. Uganda Sessional Papers C0685. The National Archives London, London, UK.

Annual Medical and Sanitary Reports, 1951. Uganda Sessional Papers C0685. The National Archives London, London, UK.

Annual Medical and Sanitary Reports, 1952. Uganda Sessional Papers C0685. The National Archives London, London, UK.

Annual Medical and Sanitary Reports, 1958. Uganda Sessional Papers C0685. The National Archives London, London, UK. 
Annual Medical and Sanitary Reports, 1960. Uganda Sessional Papers C0685. The National Archives London, London, UK.

Asare E, Tompkins AM, Bomblies A, 2016a. Evaluation of a simple puddle breeding site model for malaria vectors using high resolution explicit surface hydrology simulations. PLoS One (in press).

Asare EO, Tompkins AM, Amekudzi LK, Ermert V, 2016b. A model for the evolution of temporary mosquito breeding sites evaluated with in situ observations in Ghana. Geospat Health 11:390.

Atieli H, Menya D, Githeko A, Scott T, 2009. House design modifications reduce indoor resting malaria vector densities in rice irrigation scheme area in western Kenya. Malaria J 8:108.

Ault SK, 1993. Environmental management: a re-emerging vector control strategy. Am J Trop Med Hyg 50(Suppl. 6):35-49.

Bayoh MN, Lindsay SW, 2003. Effect of temperature on the development of the aquatic stages of Anopheles gambiae sensu stricto (Diptera: Culicidae). Bull Entomol Res 93:375-81.

Bayoh MN, Lindsay SW, 2004. Temperature-related duration of aquatic stages of the Afrotropical malaria vector mosquito Anopheles gambi$a e$ in the laboratory. Med Vet Entomol 18:174-9.

Beck A, 1970. A history of the British medical administration of East Africa, 1900-1950. Ph.D. thesis. Harvard University Press, Cambridge, MA, USA.

Birkett C, Murtugudde R, Allan T, 1999. Indian Ocean climate event brings floods to east Africa's lakes and the Sudd marsh. Geophys Res Lett 26:1031-4.

Black E, Slingo J, Sperber KR, 2003. An observational study of the relationship between excessively strong short rains in coastal east Africa and Indian Ocean sst. Mon Weather Rev 131:74-94.

Bødker R, Kisinza W, Malima R, Msangeni H, Lindsay S, 2000. Resurgence of malaria in the Usambara mountains, Tanzania, an epidemic of drug-resistant parasites. Glob Chan Hum Health 1:134-53.

Bradley R, Diaz H, Kiladis G, Eischeid J, 1987. ENSO signal in continental temperature and precipitation records. Nature 327:497-501.

Caminade C, Kovats S, Rocklov J, Tompkins AM, Morse AP, Colón-González FJ, Stenlund H, Martens P, Lloyd SJ, 2014. Impact of climate change on global malaria distribution. P Natl Acad Sci USA 111:3286-91.

Carswell G, 2003. Continuities in environmental narratives: the case of Kabale, Uganda, 1930-2000. Environ Hist Camb 9:3-29.

Carswell G, 2007. Cultivating success in Uganda: Kigezi farmers and colonial policies. James Currey Publ., Martlesham, UK.

Carter R, Mendis KN, 2002. Evolutionary and historical aspects of the burden of malaria. Clin Microb Rev 15:564-94.

Christy JR, 2013. Monthly temperature observations for Uganda. J Appl Meteorol Clim 52:2363-72.

Cox J, Hay SI, Abeku TA, Checchi F, Snow RW, 2007. The uncertain burden of Plasmodium falciparum epidemics in Africa. Trends Parasitol 23:142-8.

Craig MH, Snow RW, le Sueur D, 1999. A climate-based distribution model of malaria transmission in sub-Saharan Africa. Parasitol Today 15:105-11.

Depinay JM, Mbogo CM, Killeen G, Knols B, Beier J, Carlson J, Dushoff J, Billingsley P, Mwambi H, Githure J, Toure AM, McKenzie FE, 2004. A simulation model of African Anopheles ecology and population dynamics for the analysis of malaria transmission. Malaria J 3:29.

De Zulueta J, Kafuko G, Cullen J, Pedersen C, 1961. The results of the first year of a malaria eradication pilot project in Northern Kigezi (Uganda). East African Med J 38:1-26.

De Zulueta J, Kafuko G, McCrae A, Cullen J, Pedersen C, Wasswa D, 1964. A malaria eradication experiment in the highlands of Kigezi (Uganda). East African Med J 41:102.

Doyal L, Pennell I, 1979. The political economy of health. Pluto Press,
London, UK

Eckhoff PA, 2011. A malaria transmission-directed model of mosquito life cycle and ecology. Malaria J 10:10.

Ermert V, Fink AH, Morse AP, Paeth H, 2012. The impact of regional climate change on malaria risk due to greenhouse forcing and land-use changes in tropical Africa. Environ Health Persp 120:77-84.

Findlay GM, 1946. The internal combustion engine and the spread of disease. Brit Med J 2:979-82.

Fontaine RE, Najjar AE, Prince JS, 1961. The 1958 malaria epidemic in Ethiopia. Am J Trop Med Hyg 10:795-803.

Garnham PC, 1945. Malaria epidemics at exceptionally high altitudes. Brit Med J 2:45.

Garnham PC, Wilson DB, Wilson ME, 1948. Malaria in Kigezi, Uganda. J Trop Med Hyg 51:156-9.

Gething PW, DL Smith, AP Patil, AJ Tatem, RW Snow, SI Hay, 2010. Climate change and the global malaria recession. Nature 465:342-5.

Githeko AK, Shiff KN, 2005. The history of malaria control in Africa: lessons learned and future perspectives. Taylor \& Francis, London, UK.

Goddard L, Graham NE, 1999. Importance of the Indian Ocean for simulating rainfall anomalies over eastern and southern Africa. J Geophys Res 104:19.

Goldewijk KK, Battjes JJ, 1997. A hundred year (1890-1990) database for integrated environmental assessments (HYDE, version 1.1). Available from: www.pbl.nl/sites/default/files/cms/ publicaties/422514002.pdf

Goldewijk KK, Beusen A, Janssen P, 2010. Long-term dynamic modeling of global population and built-up area in a spatially explicit way: Hyde 3.1. The Holocene 20:565-73.

Hay SI, Cox J, Rogers DJ, Randolph SE, Stern DI, Shanks GD, Myers MF, Snow RW, 2002a. Climate change and the resurgence of malaria in the East African highlands. Nature 415:905-9.

Hay SI, Rogers DJ, Randolph SE, Stern DI, Cox J, Shanks GD, Snow RW, 2002b. Hot topic or hot air? Climate change and malaria resurgence in East African highlands. Trends Parasitol 18:530-4.

Himeidan YE, Kweka EJ, 2012. Malaria in East African highlands during the past 30 years: impact of environmental changes. Front Physiol $3: 315$.

Hoshen MB, Morse AP, 2004. A weather-driven model of malaria transmission. Malaria J 3:32.

Jones AE, Morse AP, 2010. Application and validation of a seasonal ensemble prediction system using a dynamic malaria model. J Clim 23:4202-15.

Jones AE, Morse AP, 2012. Skill of ENSEMBLES seasonal re-forecasts for malaria prediction in West Africa. Geophys Res Lett 39:707.

Kaplan A, Cane MA, Kushnir Y, Clement AC, Blumenthal MB, Rajagopalan B, 1998. Analyses of global sea surface temperature 1856-1991. J Geophys Res 103:567-8.

Kelly-Hope L, McKenzie FE, 2009. The multiplicity of malaria transmission: a review of entomological inoculation rate measurements and methods across sub-Saharan Africa. Malaria J 8:19.

Kienberger S, Hagenlocher M, 2014. Spatial-explicit modeling of social vulnerability to malaria in East Africa. Int J Health Geogr 13:29.

Kilian A, Langi P, Talisuna A, Kabagambe G, 1999. Rainfall pattern. El Niño and malaria in Uganda. T Roy Soc Trop Med H 93:22-3.

Kitron U, Spielman A, 1989. Suppression of transmission of malaria through source reduction: antianopheline measures applied in Israel, the United States, and Italy. Rev Infect Dis 11:391-406.

Konradsen F, van der Hoek W, Amerasinghe FP, Mutero C, Boelee E, 2004. Engineering and malaria control: learning from the past 100 years. Acta Trop 89:99-108.

Latif M, Dommenget D, Dima M, Grötzner A, 1999. The role of Indian 
Ocean sea surface temperature in forcing east African rainfall anomalies during December-January 1997/98. J Climate 12:3497-504.

Lindblade KA, Walker ED, Onapa AW, Katungu J, Wilson ML, 1999. Highland malaria in Uganda: prospective analysis of an epidemic associated with El Niño. T Roy Soc Trop Med H 93:480-7.

Lindblade KA, Walker ED, Onapa AW, Katungu J, Wilson ML, 2000. Land use change alters malaria transmission parameters by modifying temperature in a highland area of Uganda. Trop Med Int Health 5:263-74.

Lindsay SW, Emerson PM, Charlwood JD, 2002. Reducing malaria by mosquito-proofing houses. Trends Parasitol 18:510-4.

Lindsay SW, Martens WJ, 1998. Malaria in the African highlands: past, present and future. B World Health Organ 76:33-45.

Lunde TM, Korecha D, Loha E, Sorteberg A, Lindtjørn B, 2013. A dynamic model of some malaria-transmitting anopheline mosquitoes of the Afrotropical region. I. Model description and sensitivity analysis. Malaria J 12:1.

Lwetoijera DW, Kiware SS, Mageni ZD, Dongus S, Harris C, Devine GJ, Majambere S, 2013. A need for better housing to further reduce indoor malaria transmission in areas with high bed net coverage. Parasite Vector 6:57.

MacLeod DA, Jones A, Di Giuseppe F, Caminade C, Morse AP, 2015. Demonstration of successful malaria forecasts for Botswana using an operational seasonal climate model. Environ Res Lett 10:044005.

Mandal S, Sarkar RR, Sinha S, 2011. Mathematical models of malaria. A review. Malaria J 10:202.

Martens P, Hall L, 2000. Malaria on the move: human population movement and malaria transmission. Emerg Infect Dis 6:103-9.

Matson A, 1957. The history of malaria in Nandi. East African Med J $34: 431$.

McCrae AWR, 1975. Malaria. In: Hall SA, Langlands BW, eds. Uganda atlas of disease distribution. East African Publishing House, Nairobi, Kenya, pp 30-5.

Morris HF, 1978. Introduction. In: Rubin N, ed. Annual departmental reports relating to Uganda. EP Microform Ltd, Wakefield, UK. Available from: images.crl.edu/135.pdf

Mouchet J, Manguin S, Sircoulon J, Laventure S, Faye 0, Onapa AW, Carnevale P, Julvez J, Fontenille D, 1998. Evolution of malaria in Africa for the past 40 years: impact of climatic and human factors. J Am Mosquito Contr 14:121-30.

Nkurunziza H, Gebhardt A, Pilz J, 2011. Geo-additive modelling of malaria in Burundi. Malaria $\mathrm{J}$ 10:1-7.

Omumbo JA, Lyon B, Waweru SM, Connor SJ, Thomson MC, 2011. Raised temperatures over the Kericho tea estates: revisiting the climate in the East African highlands malaria debate. Malaria J 10:12.

Pascual M, Ahumada JA, Chaves LF, Rodó X, Bouma M, 2006. Malaria resurgence in the East African Highlands: temperature trends revisited. P Natl Acad Sci USA 103:5829-34.

Pascual M, Cazelles B, Bouma MJ, Chaves LF, Koelle K, 2008. Shifting patterns: malaria dynamics and rainfall variability in an African highland. P Roy Soc Lond B Bio 275:123-32.

Patz JA, Campbell-Lendrum D, Holloway T, Foley JA, 2005. Impact of regional climate change on human health. Nature 438:310-7.

Piontek F, Müller C, Pugh TA, Clark DB, Deryng D, Elliott J, Colón González Fde J, Flörke M, Folberth C, Franssen W, Frieler K, Friend AD, Gosling SN, Hemming D, Khabarov N, Kim H, Lomas MR, Masaki Y, Mengel M, Morse A, Neumann K, Nishina K, Ostberg S, Pavlick R, Ruane AC, Schewe J, Schmid E, Stacke T, Tang Q, Tessler ZD, Tompkins AM, Warszawski L, Wisser D, Schellnhuber HJ, 2014. Multisectoral climate impact hotspots in a warming world. P Natl Acad Sci USA 111:3233-8.
Prothero RM, 1961. Population movements and problems of malaria eradication in Africa. B World Health Organ 24:405.

Roberts J, 1956. Pyrimethamine (Daraprim) in the control of epidemic malaria. J Trop Med Hyg 59:201.

Roberts J, 1964. The control of epidemic malaria in the highlands of western Kenya. I. Before the campaign. J Trop Med Hyg 67:161.

Sevilla-Casas E, 1993. Human mobility and malaria risk in the Naya river basin of Colombia. Soc Sci Med 37:1155-67.

Shanks GD, Hay SI, Omumbo JA, Snow RW, 2005. Malaria in Kenya's western highlands. Emerg Infect Dis 11:1425.

Siraj AS, Santos-Vega M, Bouma MJ, Yadeta D, Carrascal DR, Pascual M, 2014. Altitudinal changes in malaria incidence in highlands of Ethiopia and Colombia. Science 343:1154-8.

Steyn J, 1946. The effect on the anopheline fauna of cultivation of swamps in Kigezi district, Uganda. East African Med J 23:163-9.

Talisuna A0, Noor AM, Okui AP, Snow RW, 2015. The past, present and future use of epidemiological intelligence to plan malaria vector control and parasite prevention in Uganda. Malaria J 14:158.

Tatem AJ, 2014. Mapping population and pathogen movements. Int Health 6:5-11.

Tatem AJ, Smith DL, 2010. International population movements and regional Plasmodium falciparum malaria elimination strategies. $\mathrm{P}$ Natl Acad Sci USA 107:222-7.

Tatem AJ, Adamo S, Bharti N, Burgert CR, Castro M, Dorelien A, Fink G, Linard C, John M, Montana L, Montgomery MR, Nelson A, Noor AM, Pindolia D, Yetman G, Balk D, 2012. Mapping populations at risk: improving spatial demographic data for infectious disease modeling and metric derivation. Popul Health Metr 10:8.

Thomson MC, Doblas-Reyes FJ, Mason SJ, Hagedorn R, Connor SJ, Phindela T, Morse AP, Palmer TN, 2006. Malaria early warnings based on seasonal climate forecasts from multi-model ensembles. Nature 439:576-9.

Tompkins AM, Di Giuseppe F, 2015. Potential predictability of malaria using ECMWF monthly and seasonal climate forecasts in Africa. J Appl Meteor Clim 54:521-40.

Tompkins AM, Ermert V, 2013. A regional-scale, high resolution dynamical malaria model that accounts for population density, climate and surface hydrology. Malaria J 12:65.

Tompkins AM, McCreesh N, 2016. Migration statistics relevant for malaria transmission in Senegal derived from mobile phone data and used in an agent-based migration model. Geospat Health 11:408.

Venzke S, Latif M, Villwock A, 2000. The coupled GCM ECHO-2. Part ii: Indian ocean response to enso. J Climate 13:1371-83.

Verdon DC, Franks SW, 2005. Indian Ocean sea surface temperature variability and winter rainfall: Eastern Australia. Water Resour Res 41:1-10.

Walker K, Lynch M, 2007. Contributions of Anopheles larval control to malaria suppression in tropical Africa: review of achievements and potential. Med Vet Entomol 21:2-21.

Wandiga SO, Opondo M, Olago D, Githeko A, Githui F, Marshall M, Downs T, Opere A, Oludhe C, Ouma GO, Yanda PZ, Kangalawe R, Kabumbuli R, Kathuri J, Apindi E, Olaka L, Ogallo L, Mugambi P, Sigalla R, Nanyunja R, Baguma T, Achola P, 2010. Vulnerability to epidemic malaria in the highlands of Lake Victoria basin: the role of climate change/variability, hydrology and socio-economic factors. Climatic Change 99:473-97.

Wesolowski A, Eagle N, Tatem AJ, Smith DL, Noor AM, Snow RW, Buckee C0, 2012. Quantifying the impact of human mobility on malaria. Science 338:267-70. 